\title{
An Analysis of Ghanaian Tertiary ESL Classroom Lectures: The Case of Achievement Communicative Strategies
}

\author{
Charlotte Fofo Lomotey (Corresponding author) \\ Department of Applied Linguistics, University of Education, Winneba
}

Ghana

Joyce Debrah-Amofah

Department of General Studies, Takoradi Technical University, Takoradi

Ghana

Received: April 9, 2021 Accepted: May 15, $2021 \quad$ Published: May 18, 2021

doi:10.5296/ijele.v9i2.18655 URL: https://doi.org/10.5296/ijele.v9i2.18655

\begin{abstract}
Whenever we speak, we use specific strategies to help us achieve our communication goals (Nakatani, 2006). These can be reduction or achievement strategies. Achievement strategies are used by teachers and students to help them overcome their inadequate linguistic knowledge (Trihastuti \& Zamzani, 2018) so that lessons can ensue smoothly. This study sought to investigate achievement communicative strategies used by lecturers and students in two public tertiary institutions in Ghana. An observational descriptive case study design was adopted with 12 Communication Skills classrooms purposively sampled from the two institutions. Lesson recording and observation were the instruments used to collect data and analysed using conversation analysis. The analysis revealed that strategies such as code-switching, all-purpose words, literal translation, and appeal for assistance were employed whenever lecturers and students realized they had problems expressing their intended meaning and they needed to solve the problems. It was revealed that the functions of the strategies were for repair to reach communication goals, to convey meaning, to ensure language accuracy, and to request for explanation and clarification. It also showed that the reasons for using the strategies were to avoid a break in the communication process, to develop learner autonomy, and to deepen lecturer-student interaction. Accordingly, it is recommended that such strategies (and others) should be incorporated into the teaching and
\end{abstract}


learning process to create opportunities for meaningful communication to enable lecturers and students develop their communicative competence.

Keywords: communicative strategy, achievement strategies, communication breakdown, lecture, tertiary education, language deficiency, compensating

\section{Introduction}

The term communication is derived from the Latin word "communis" which means to share and is the process in which a sender encodes the message and sends it to the receiver. The receiver in turn decodes it and responds to it. Communication can happen anywhere and anytime without limitations of space and time. According to Huff and Christensen (2018), communication is a means of producing a message to be received by another. They note that it evokes a shared understanding of meaning which is developed through social interaction or among participants. It is therefore worthy to note that people send and receive messages and negotiate meaning via communication. In the classroom, learners can cope with such communication problems by using communicative strategies. A strategy often means "a set of procedures for accomplishing something" (Dörnyei \& Scott, 1997, p. 179), but the term appears as a technical one in fields as diverse as social psychology and game theory.

One of the earliest definitions of the term was offered by Færch and Kasper (1983). They state that communication strategies are "potentially conscious plans which are used by an individual to solve a problem to reach a specific communication goal" (p. 36). Lafford (2004, p. 204) viewed communicative strategies as "strategies used by L2 learners in a conscious attempt to bridge a perceived communication gap either caused by the learners' lack of L2 knowledge (resource deficit), problems with his or her own performance, or problems resulting from interaction with an interlocutor". Dörnyei (1995) pointed out that communication strategies develop learners' oral proficiency. To add to this, Trihastuti and Zamzani (2018) observed that communication strategies help students and teachers to make their points clearer and to gain proficiency, especially in situations where they lack particular registers to express certain difficult concepts. As such, students need to develop communicative competence, especially strategic competence, for them to overcome the burdens in listening and speaking skills. Hymes (1972) proposed the concept of communicative competence and was further developed by Canale and Swain (1980) for the purposes of teaching. In their conceptualization, they identified four components of communicative competence: grammatical, sociolinguistic, discourse, and strategic competence.

Dörnyei and Thurrell (1991) maintained that strategic competence includes "the ability to get one's meaning across successfully to communicative partners, especially when problems arise in the communication process" (p. 17). Brown (2000) summarized the definition of strategic competence as the way interlocutors manage language to achieve communicative goals. Similarly, Alptekin (2002) stressed that strategic competence requires the understanding of communication strategies that one can use to compensate for 
communicative difficulties and keep the communicative channel open. In agreement with these explanations, students can be encouraged to develop their communicative competence by building their strategic competence to effectively use communication strategies whenever they face communication problems. As such, Trosborg (1994) argued that "strategic competence is a compensatory element which enables a speaker to make up for gaps in his knowledge system or lack of fluency by means of communication strategies" (p. 211).

Khanji (1996) identified three components of communicative strategies: 1) a communication difficulty owing to target language inadequacy, 2) student awareness of the problem, and 3) a solution to overcome it. In addition, Dörnyei and Scott (1997) asserted that oral communication is an interactive process in which an individual alternately takes the roles of speaker and listener. They state that "one can be conscious of a language problem, the intent or attempt to solve this problem, the repertoire of potentially applicable communication strategies, the way to communication strategy, the use of a less-than-perfect stopgap device" (p. 184). According to Færch and Kasper (1983), learners have a choice between two approaches when they are confronted with the challenge of conveying a message: They can either evade or avoid the problem by adjusting his ends to his means (reduction strategies) or confront the problem and try to achieve his communicative goal by adjusting his means to his ends (achievement strategies). The reduction strategies help change the goal of expressing, while the achievement strategies help to develop an alternative plan to express the original intended meaning (Færch \& Kasper, 1983). The present study examines the achievement communicative strategies used by students and lecturers in two public tertiary institutions in Ghana. According to Abura (1998), effective communication is important to student success. This requires the two parties to play essential roles in the communication process, as such roles are conducive to effective lesson delivery and teacher-student interaction.

Teachers constantly transmit new knowledge to students (Habeeb, 2014), and so they not only help to improve students' communication but also ensure that their own communication skills are effective. Thus, they need to be highly skilled in all these areas to excel in their profession. Communication is, therefore, an indispensable factor in the teaching-learning process (Duta \& Rafaila, 2014). Accordingly teachers and students find communicative strategies to be efficient means through which they can convey their ideas and eliminate the communication gaps created during lesson delivery. More specifically, students use these strategies to raise their language awareness, solve any problems that their interlocutors may have during communication and develop their oral proficiency (Sato et al., 2019).

Nevertheless, in reality, research has shown the contrary: both students and teachers are confronted with some challenges in communication (Jahbel, 2019). Communication is both receptive and expressive. Teachers, therefore, need to be skilled at listening to their students as well as explaining things clearly. They must be able to break down complex ideas into simpler parts and smaller steps to transmit to their students. Also, teachers should understand their students and adapt to the needs of the individual. Because teacher-student interaction is very crucial in the learning environment, effective teaching is teaching that explores ways to engage the student's mind with different strategies and approaches. In fact, the reverse also holds good, especially in today's context of enormous materials available through the Internet 
(Habeeb, 2014). Rather than give up, learners use a collection of strategy types at intermediate levels though they usually have their own choices for specific types. Due to communication difficulties, teachers may be unwilling to speak, thereby raising their level of communication apprehension and lowering their perception of communicative competence. As such, speakers are sometimes afraid to interact with others, and this affects them negatively. Finally, these communicative challenges reduce teachers' self-confidence.

\subsection{Achievement Strategies}

Færch and Kasper (1983) developed a detailed taxonomy of communication strategies; reduction strategies and achievement strategies. According to Færch and Kasper (1983, p. 36), "communication strategies can be firstly classified two basically different ways in which learners might behave when faced with problems while they are communicating". These two ways are avoidance behaviour and achievement behaviour. In their opinion, avoidance behaviour governs reduction strategies while achievement behaviour governs achievement strategies. As already indicated, learners communicate by a reduced system to avoid producing incorrect utterances or attempt to solve the problem by expanding the communicative resources available for them, thereby achieving the aim of communication. Dörnyei pointed out that such strategies are "normally termed achievement or compensatory strategies" (p. 57) while Færch and Kasper (1983) called them achievement strategies. Brown (2000) considered compensatory strategies as strategies that help make up for the knowledge that we do not possess. They could be explained as communication strategies used by learners to compensate for limitations in their language. Consequently, it is reasonable to assume that achievement strategies can correspond to compensatory strategies. This adoption is based on the assertion that compensatory/achievement strategies enable learners to rely on available resources as an alternative plan to help them reach their communicative goals (Nakatani, 2006).

Johnstone (1989, p. 71) proposed a list of achievement strategies with the belief that learners find alternative language resources to convey meaning solution for reaching the communication goal and try to overcome their communication difficulties. These strategies are as follows: Code-switching, literal translation, foreignizing, word coinage, approximation, circumlocution, appeal for help, and all-purpose words. Code-switching occurs in formal language situations, and as a discourse strategy, is found in use in varied domains of language usage. Usually, we observe bilinguals mixing two languages when speaking (Adjei, 2010). Code-switching is certainly a communicative strategy, but it is also the case that code-switching is a category of its own, outside of the study of communicative strategies. Literal translation takes place when a speaker literally translates a lexical item, idiom, compound word, or structure from L1 to L2 while nonlinguistic signals include mime, gesture, facial expression, or sound imitation (Brown, 2000, pp. 128 -129).

With regards to foreignizing, Kim (2019) observed that it is employed when a speaker adjusts an L1 word/phrase to the L2 phonology and/or morphology. Thus, the word/phrase is pronounced as if it is an L2 word. According to Yule (2020), word coinage is the process 
through which completely new words are created either deliberately or accidentally. Approximation is when a speaker uses another word which expresses the meaning of the target lexical item as closely as possible (e.g., ship for a sailboat). Circumlocution is the act of describing or exemplifying the target object of an action (e.g., my mother's mother 'for grandmother'). Dörnyei (1995) explains this strategy as one where the speaker replaces a word by describing it. Appeal for help is utilized by asking for aid from the interlocutor either directly. The interlocutor can be the listener or audience. In this study, it has also been found that the speaker can seek help from a book that contains information needed for the interaction. This can be done in the form of a question (e.g., you see what I mean...?) or indirectly (e.g., rising intonation, pause, eye contact, puzzled expression) (Dörnyei, 1995, p. 58). All-purpose words are used by extending a general, empty lexical item to contexts where specific words are lacking (e.g., the overuse of thing, stuff, what-do-you call-it, thingies).

While communicative strategies have been studied in different contexts (e.g., Arjpru \& Chattiwat, 2017; Jamshidnejad, 2020; Kenza, 2020; Kim, 2019; Sato et al., 2019), none is found in Ghana. More importantly, there is no known study on the use of achievement strategies in the classroom specifically, and in any other context in general. Meanwhile, results of such studies show how speakers may sometimes benefit from being aware of the advantages of asking for help, instead of just giving up or using a native language item. When these strategies are identified, it is possible to help improve the way lecturers teach communicative classes and so assist students with limited oral proficiency to achieve better communication. The present study therefore, adopted a qualitative approach to analyze data collected from 16 classrooms from two public tertiary institutions to deepen our understanding of how these strategies are used by both lecturers and students to facilitate communication and effective lesson delivery in the classroom. It aims to examine the types of achievement strategies used by lecturers and students of the two institutions and to describe the reasons for the use of the strategies in the ESL classroom. To achieve these, the following research questions are posited:

1. What are the achievement communicative strategies used by first-year lecturers and students in the ESL Communication Skill classroom in Ghanaian tertiary institutions?

2. What are the functions of the achievement communicative strategies in the Communication Skill classroom?

3. Why do the lecturers and students use achievement communicative strategies in the Communication Skill classroom?

\subsection{Theoretical Framework}

Typically, communication strategies have been studied from two significant theoretical perspectives. These are psycholinguistic and interactional approaches (Dobao \& Martínez, 2007). According to Wagner and Firth (1997), the psycholinguistic approach treats communication strategies in relation to both overt and covert elements by classifying its cognitive bases, while the interactional approach considers communication strategy as an overt phenomenon, rendered through participants' actions. The framework adopted for the 
study is thus a combination of the two approaches. Tarone (1980) considered communication explicitly in terms of interaction. Tarone argued that learners' linguistic inadequacy warrants that interlocutors employ communication strategies to convey meaning in question to one another. Primarily, the interactional approach is based on the interaction process between language learners and their interlocutors and the negotiation of meaning (Tarone, 1980).

Tarone (1980) further observed that by using a communication strategy, interlocutors mutually agree on meaning in situations where they do not share the requisite meaning structures. Bialystok (1990) also advanced the argument that "the familiar ease and fluency learners sail from one idea to the next in the first language is shattered by some gap in the knowledge of a second language" (p. 1). This means that it may not always be possible for ESL learners to exhibit the same ease as native English speakers. It is important to emphasize that learners need to overcome these gaps. The interactional approach accepts both reduction strategies and achievement strategies, and with these, participants try to come up with an appropriate strategy to get out of the difficulty when things go wrong in a conversation. Thus, for language learners to receive access to comprehensible input, feedback, and modified output to achieve effective communication, they must negotiate input to ensure that the input is modified for understanding.

Færch and Kasper (1983) have proposed a psycholinguistic account of communication strategies within a model of speech production, resting on the division between planning and execution. From this view, they adopted the criteria of process or plan, conscious or unconscious, problem-oriented, or problem-free approach. They proposed two possible strategies for solving a communication problem: Avoidance and achievement strategies. In avoidance strategies, learners find an alternative solution for reaching the original goal through whatever sources are available while the latter strategies are used when learners have difficulties retrieving specific language items. While avoidance strategies include formal reduction strategies, achievement strategies include compensatory strategies and retrieval strategies. Therefore, the psycholinguistic view of communication strategies has been associated mainly with strategies for overcoming limitations in lexical knowledge. Despite the differences in terminology and classifying dimension, the taxonomic systems agree on the type of strategic solutions motivating learners either to reduce or achieve their communicative goals because of (the assessment of) the available resources at hand. Looking at the two perspectives, Mali (2007) noted that it is possible for the communicative strategy to start off as a cognitive process and end as an interactional entity. It is therefore suggested that it is important to combine the two approaches into a theoretical framework in a study of achievement strategies in the ESL classroom. Hence, as one communicates, they think of whatever they intend to say before they can use it in the interaction.

\section{Method}

2.1 Research Approach and Design 
The study is guided by the qualitative approach. Creswell (2014) opined that the qualitative approach involves exploring and understanding the meaning individuals or groups attribute to a social or human problem. This design makes use of data gathered in the setting of the participants and analysed inductively in order to make meaningful interpretations. Amedahe (2002) explained that in every research study, the choice of a particular research design must be appropriate to the subject under investigation and that the various designs in research have specific advantages and disadvantages. An observational descriptive case study design was appropriate to this study because it offered the opportunity to access data in real natural situations. The case study design is one of the qualitative research designs which allows an investigation to real-life events or the conduct of in-depth analysis, usually over a limited time (Yin, 2003). It also helps to explore an area such as the use of achievement strategies, where studies are non-existent in Ghana in order to explicitly discover and fully understand their use as pertains in the classroom. This view ensures that the very nature of the phenomenon that is being researched is unique and not open to generalization beyond the study participants. This, to a large extent, enabled an examination of achievement communicative strategies usage in natural settings in the two institutions as well as their functions and the reasons for their use.

\subsection{Population and Sample}

The target population for the study comprised First Year undergraduate students and their Communication Skills lecturers in two tertiary institutions in Ghana. The lecturers participated in the study because their duties deal directly with teaching communication skills in the institutions. Hence, they were able to provide enough data for the study. In all, 16 classes; 8 in each case, were chosen for data collection. This number is considered adequate based on the fact that the study aimed at examining in more detail the communicative strategies used in the classrooms. The purposive sampling technique was used for the study. According to Creswell (2014), purposive sampling is the situation where researchers intentionally select individuals or groups and sites to understand a phenomenon. The reason for settling on purposive sampling is that it is less expensive, less time-consuming and free from bias. It also gives better results if the investigator is unbiased and has the capacity of keen observation and sound judgment while ensuring intensive study of the selected items (Babbie, 2015).

\subsection{Research Instruments and Data Collection}

Audio-recorded lessons and observation were used as instruments for data collection. Spoken language was used in order to detect the achievement communicative strategies based on the assumption that speech is more spontaneous than writing and studying speech helps us to get closer to real communication. Digital audio tape recorders were used for the recordings. As soon as we obtained permission to go ahead, we connected the recorders to PZM microphones and positioned each at a place close to the lecturer in each classroom to accurately capture speech. Here, only the lecturer and the students were left in the room to allow them feel comfortable with their talk. Each recording lasted 2 hours and this produced a total of 32 hours of data obtained from all the 16 lessons. Topics covered in the lectures include concord, determiners, parts of speech, scanning and skimming, types of reading, and 
reading faults. For the observation, we chose participant observation to help us understand the reasons for and functions of the strategies used. Similarly to the recording, we visited each class once to observe. Once again, once we obtained permission, each of us visited and observed eight classes, one at a time. We had notebooks in which we recorded our observations. We wrote down the type of strategies used and the functions they were used for. Guided by literature, we also identified and wrote down the reasons for the use of the strategies. Each observation section lasted 40 minutes, yielding a total of 9.5 hours of observation.

\subsection{Data Analysis}

A conversational-analytic method was followed for the analysis. The utterances in the audio recordings were transcribed for appropriate analysis. Here, the tapes were played back and all utterances typed verbatim. The play back was done many times to capture exactly what was said. After the transcription, all achievement communicative strategies were identified. Although there were other strategies captured in the recording, we did not consider them because they did not fall into the class of achievement strategies and so were not the focus of the research. Once an achievement strategy was identified, the context within which it was used was also marked to help with easy interpretation. In all, there were four achievement strategies identified in the data. The observation notes were also transcribed for easy access. Each identified function or reason was attached to the particular strategy used to achieve it and grouped. This yielded four functions and three reasons.

\subsection{Reliability and Validity}

O'Leary (2017) observes that researchers aim to verify that their findings are consistent with the raw data they collected. They also want to ensure that if some other researchers were to look over the data, they would arrive at similar findings, interpretations, and conclusions about the data. In this study, the methodology, the methods and the data analysis have been thoroughly described to allow researchers to make such transfer. This study passes the test for dependability because all the important details as regards the research practices that were followed have been presented to position researchers to fully comprehend the enquiry processes followed and their effectiveness. As Shenton (2004) explains, there must be "in-depth methodological description to allow integrity of research results to be scrutinized" (p. 73). Accordingly, a thorough methodological description is offered in this study to satisfy the test for confirmability. For reliability, the transcripts were checked and re-checked with two experts who have extensive knowledge of English and Twi (the L1 used). Where there were disagreements, they were resolved after discussions and cleaning of the transcripts.

\section{Results and Discussion}

The results are discussed in the next three subsections. The first subsection focuses on the types of achievement strategies used by the lecturers and their students and these were four: code-switching, literal translation, all-purpose words, and appeal for assistance. The functions of the strategies identified are discussed in the second subsection. The strategies were found 
to be used for repair to reach the goal of communication, to convey meaning, to ensure language accuracy, and to request for more explanation. The final subsection presents results regarding the reasons for the use of the strategies. These were to avoid break in the communication process, to deepen teacher-student interaction, and to develop learner autonomy.

\subsection{Types of Achievement Strategies}

The types of achievement strategies identified in the data are code-switching, all-purpose words, literal translation, and appeal for assistance. These are discussed with illustrations as follows:

\subsubsection{Code-switching}

Code-switching is where an L1 word is used with L1 pronunciation while speaking in L2. It is a natural and frequent phenomenon tightly connected to the bilingual environment. Code-switching is using a L1 word with L1 pronunciation while speaking in L2. According to László (2017), foreign language learners may face various communication problems when their language lacks the necessary resources. Code-switching occurs when a speaker knows more than one language; that is why the study of code-switching can be seen as a part of the study of bilingualism (Meyerhoff, 2015). This assertion is based on the evidence from Extract 1 as follows:

\section{Extract 1}

$1 \quad$ S: Sir close reading is when you read your notes closely

2 L: Ah Ogyam $\varepsilon$ ne nso bio? [you, today too?] What's your name?

3 L: Do you understand?

$4 \quad$ S: Kakra kakra [bit by bit] (laughter)

5 L: You need to do a lot of reading

6 L: Explain why mouthing of words is a fault. Do something. Ye biribi wate [do 7 something!].

8 L: You see ye bi [take part]. Wo te mpo a ye na te. [it's better you try and not get

9 it] I hope I'm making sense. Y $\varepsilon$ te because obi nim obi kuro a adec be kye so 10 [proverb]

11 S: Me ye bi [I do something]

In extract 8, the lecturer switched from the target language to the L1. The lecturer asked what close reading was. A student responded that close reading is when you read your notes closely. When the lecturer wanted to know the name of the student, he switched from the target language to L1 as seen in line $\mathbf{2}$. In line $\mathbf{3}$, the lecturer then inquired if the students understood what he was teaching and in line 4, a student answered in the L1. Again, the lecturer asked what reading faults were, and also switch from the target to the L1 in order to maintain the conversation. He did not switch to L1 because he lacked the suitable register but 
probably he wanted to sustain the conversation. In lines $\mathbf{8}$ and $\mathbf{9}$, the lecturer was encouraging the students to try the questions he had given them and he switched to the L1. The student also responded in the $\mathrm{L} 1$ that he would try by saying me ye bi. This can be related to the work of Kenza, 2020) on code-switching when she asserts that speakers resort to the native language because they share the same native language with their listeners. This invariably creates a sense of belongingness. Another instance of code-switching is illustrated in Extract 2 as follows:

\section{Extract 2}

1 L: Pay attention to the spelling okay? How can you be writing A verb instead of adverb?

2 Gyama wo krom 'd' ni ho? [don't you have 'd' in your hometown?] (Laughter)

3 S: $\varepsilon y \varepsilon$ nokware paaa [That's certainly true] (Laughter)

4 L : wo kyerew nsem hunu a wo nim [you know when you don't write anything good]

5 S: (Laughter)

Looking at Extract 2, we see that the lecturer tried to draw the attention of the student to the fact that he should have inserted [d] into a verb to get adverb and not $a$ verb. The lecturer corrected the student by asking him if his townsfolk do not use the sound [d] in the L1. Thus, although the lecturer knows that the students can speak English, he still decided to fall on the L1 to alert the student to the correct spelling of the word adverb. In this extract, we argue that code-switching was not used because of a lack of a linguistic equivalent in the L2; rather, he decided to use the linguistic resources familiar to the students to facilitate comprehension. Apart from using code-switching to help both the lecturer and the student to compensate for any language deficiencies (e.g., Adjei, 2010), it also allowed them to keep the flow of communication and to project their positive face. As the use of the L1 may be seen as face threatening, the lecturer did so to show that he recognizes the need to maintain common ground with the students so that the communication flow can be maintained.

\subsubsection{Literal Translation}

Literal translation occurs when a lexical item, idiom, compound word, or structure is presented in English as if it is being said in the native language. This is illustrated in Extract 5 when the lecturer wanted to introduce the topic for the day's lesson; he translated it literally from the L1 into the target language as shown:

\section{Extract 3}

1 L: Hello errm today I want us to look at something. The topic is close reading.

2 S: Sir close reading is when you read your notes closely

3 L: Ah Ogyam $\varepsilon$ ne nso bio? [it's strange!] You again? What's your name?

4 S: Ato

5 L: Can somebody give us an example? 
S: We will buy the new phone here.

In line 1, the lecturer makes use of literal translation. This is seen in the direct translation $\varepsilon n \varepsilon$ me pe se ye hwe biribi from L1 to today I want us to look at something (L2) before he mentions the topic. This is possible because rather than starting right away with the L2, he brings out what is readily available in this L1 repertoire before he remembers exactly what the topic is. And, while he tries to start the class with something, he ends up translating literally from the L1 into English. This outcome is supported by Hedge (2000) who reveals that most L2 speakers use strategies which involve the use of first language. Thus, the lecturer used the language switch and literal translation because he wanted to make sure that his students understood his message. And, because the students are also familiar with the L1, comprehension became easier, helping to minimize mistakes in the course of communication.

\subsubsection{All-purpose Words}

The use of all-purpose words refers to the use of words or phrases having general meaning instead of specific words to convey the utterances. Extract 3 is an example of this. In this extract, the lecturer was introducing the topic for the lesson. With this, he used the word something which has a general meaning instead of a specific one as follows:

\section{Extract 4}

1 L: Now let's consider something. Let's look at types of adverbs

2 L: Adverb of Place: They answer the question 'where'. For example: Here,

3 There, Downstairs, and Upstairs

4 L: Example: Upstairs, my brothers quarreled.

5 L: Here the question is 'where did they quarrel? 'Upstairs'

6 L: Can somebody give us an example?

$7 \quad$ S: We will buy the new phone here.

In the interaction, the lecturer employed all-purpose words, namely "something". He first mentioned the word "something" to describe the point they were going to discuss in class. In the next utterance, he mentioned the word "topic" to replace the word "something". It would have been much better if he had directly used a specific word like "the topic" instead of the word "something" that has multi-purpose meanings, such as event, situation, or act. Another example of the use of all-purpose words is seen in Extract 5:

\section{Extract 5}

1 L: I want us to discuss something.

2 L: Have you heard about concord?

3 S: Somehow. It is but eerrm

4 L: Concord refers to the agreement relations which exist between two grammatical 
units so that when one unit displays a particular feature, the other unit will display a similar feature.

In Extract 5, the lecturer's aim is to teach concord. However, as soon as he enters the classroom, he tells the students that they are going to discuss something, rather than explicitly mentioning the topic. From the question he asks students, we get to know that the something that he is referring to is concord. While such words do not really add any information to the interaction, we can see from the extract that something was used to introduce or connect ideas that would be discussed later in the lesson. By so doing, the lecturer was able to convey some difficult words in English, without resorting to the use of the L1. Ultimately, although the lecturer appeared to have a deficiency in his vocabulary, such a strategy helped him to depend on this same linguistic repertoire to reduce the gaps in his performance (Aliakbari \& Allvar, 2009).

\subsubsection{Appeal for Assistance}

The aim of communication in the context of language itself is to communicate efficiently and use the language accordingly. Generally, students should be able to communicate in three types of discourses: interpersonal, transactional, and functional. In Extract 6, a student exhibited this by appealing to his notes. In this Extract, the lecturer was trying to define determiners. In an attempt to explain, he realized that he needed help to complete the definition so he referred to his notes for such assistance:

\section{Extract 6}

1 L: So errm yes errr today so errm we have finished with all the parts of speech.

2 Beautiful. Determiners basically are errm a group of err. They are a group of

3 errr (looks into his note book)

4 L: A determiner, also called determinative, is a word, errm phrase, or affix that

5 occurs together with a noun or noun phrase and serves to express the reference of 6 that noun or noun phrase in the context.

$7 \quad$ L: What are reading faults?

8 S: It is faults in reading

9 S: This applies to problems that can arise in the course of our readings (is that all?)

The extract shows that both lecturers and the students used appeal for help strategy. The lecturer employed the strategy by looking into his note book. On the other hand, the student asked for help by way of a question to the entire class to help him complete the definition as seen in lines 1-6. Before looking into his notebook, the lecturer stopped for a while and could not continue with the definition. After that, he continued to present the material. For the student, he stopped at the point where he posed the question. This can be interpreted as an 
indication that although both may know the content, their vocabulary was limited and so they needed help to ensure comprehension. Another example is illustrated in Extract 7 as follows:

\section{Extract 7}

1 L: That crucial feature is 'number'. Number in grammar simply refers to whether an

2 entity being talked about is singular or plural. If that entity is singular, it means it

3 is only one. Plurality refers to being more than one (1).

4 S: Like two, three, four or?

5 L: Pay attention. Singular subject is one whereas a plural subject refer to more than

$6 \quad$ one (looks into his book)

7 L: Pay attention. Singular subject is one whereas a plural subject refers to more 8 than one.

In the extract, the lecturer intended to let the students know the difference between singular and plural subjects. In line 5, he said Pay attention. Singular subject is one whereas a plural subject refer to more than one. After realizing that he made a mistake, he restructured his sentence in line 6 after consulting his notes for assistance to Pay attention. Singular subject is one whereas a plural subject refers to more than one. The lecturer corrected the word 'refer' and made it 'refers'. This was done to make the meaning clear to the students so that the discussions could be sustained. Although we typically understand this strategy as one that connotes assistance from teachers or peers (Bialystok, 1990), we see that in both, one can also consult books where the appropriate vocabulary to convey meaning may be lacked.

The analysis has revealed that the achievement communicative strategies used by the students and lecturers in the two (2) institutions are code-switching, literal translation, all-purpose words, and appeal for assistance. The class employed these strategies to keep the original communicative goal and compensate for insufficient means to retrieve the required items. It is evident from the extracts that lecturers and students employed code-switching as a communicative strategy to express themselves and to avoid break in communication. Literal translation, in addition to the all-purpose words, was also employed by the class. Again, appeal for assistance was also utilized as an achievement communication strategy by the participants as evidenced in the extracts.

\subsection{Functions of Communicative Strategies}

This objective was intended to know the functions of achievement communicative strategies in a Communication Skills classroom in the two institutions. After comparing our observation notes, we found that the use of the achievement strategies were to repair to reach the goal of communication, to convey meaning, to ensure language accuracy, for more explanation, or clarification to solve a comprehension problem (e.g., Masithoh et al., 2018, p. 6). The functions are discussed as follows:

\subsubsection{To Repair to Reach the Goal of Communication}


Repair occurs when interlocutors make the utterance accurate while transferring meanings (Dörnyei \& Scott, 1997). Errors are committed by both students and lecturers at various stages of their language learning classroom. This is sometimes due to the interference of first language or as a result of lack of appropriate linguistic resources. Some errors may also occur due to grammatical dissimilarities between students' first language and target language. These errors and mistakes have some positive and constructive aspects and also point out that the students are actively participating in the language learning process. Learners and teachers have different preferences concerning error correction and giving feedback (Nunan, 1989). According to Allwright and Bailey (1991), it is very important for teachers to know when and how to correct errors. Teachers often correct a learner's utterance simply because it was not what they had expected to hear, which are referred to as error of classroom discourse. This is seen in Extract 2, where the lecturer asked the student to add [d] to a and verb to correct it to $a d v e r b$.

\subsubsection{To Convey Meaning}

The use of appeal for assistance as a strategy was used to provide more information and explanation about a concept. This strategy is used when the interlocutor does not understand properly what was going on in the communication. Here, lecturers requested assistance from other partners (in this case, books were used) when they were faced with a deficiency in self-expression (Dörnyei \& Scott, 1997). This strategy was used when the lecturers wanted to give more information and explanation about a concept.

\subsubsection{To Ensure Language Accuracy}

According to Saif (2002), the ability to achieve communicative goals through production can be assessed according to the learners' ability to match their "communicative goals and linguistic devices at their disposal for the purpose of production" (p. 166). These achievement strategies are more focused on language accuracy rather than conveying meaning. Communicative strategies "give learners the feeling that they can increase their control over language use, play an active role, make some choices and become more responsible for what they say and how they say it" (Mariani, 2010, p. 44). This finding concurs with Alawi's (2016) study that teachers focus on oral communication and assist students to choose the most appropriate communication strategies. This also indicates that speakers make use of production strategies, attempts at using one's current linguistic system as efficiently as possible and the lecturer does that by letting the subject agree with the verb in the sentence for the student to understand.

\subsubsection{To Request for More Explanation or Clarification to Solve a Comprehension Problem}

According to Dornyei and Scott (1997), interlocutors employ the strategies to request for more explanation, clarification, or repetition to solve comprehension problems. They also request for assistance from other partners when they are faced with a deficiency in self-expression. This strategy is used in order for people to clearly understand the message that is being conveyed. This interactional perspective permits the addition of various repair mechanisms, which Tarone considers as communication strategies if their purpose was "to clarify intended 
meaning rather than simply correct linguistic form" (Tarone, 1980, p. 424). The achievement strategies assisted learners to apply the ideas of using inter-language to achieve intended meanings in English communication. Nakatani (2006) maintains that students who have high oral proficiency use fluency-oriented negotiation of meaning, and social affective strategies more effectively to keep the oral communication open. The achievement communicative strategies helped the students in this study to overcome their linguistic challenges. It is clearly observed from the interactions that students and their lecturers used the strategies in order to effectively and successfully deliver the lessons.

\subsection{Reasons for Using Achievement Communicative Strategies}

The third and final objective was to identify the reasons for using achievement strategies in the Communication Skills classroom in the two institutions. The results presented here are also based on our observation of the use of achievement strategies in the classrooms. The following reasons account for their use: to avoid break in the communication process, to deepen teacher-student interaction and to develop learner autonomy. Mariani (2010, p. 44) explains that communicative strategies "give learners the feeling that they can increase their control over language use, play an active role, make some choices and become more responsible for what they say and how they say it". The reasons are outlined as follows:

\subsubsection{Avoiding Break in the Communication Process}

It was revealed in the analysis that both the lecturers and the students used achievement strategies in order to keep the conversation going and also to avoid break in the communication process. In learning a second language, students are encouraged to communicate in classroom setting using a variety of strategies besides their dependence on the negotiation of meaning. With this, Manchón (2000) asserts that achievement strategies training may contribute to enhancing the learner's sense of security and self-confidence when he or she attempts to communicate using his/her inter-language resources, and thus attempts to communicate in the $\mathrm{L} 2$.

\subsubsection{Deepening Teacher-Student Interaction}

Interaction is of essence for any language learning environment. According to Walsh (2002), if the teacher understands how the process of interaction takes place in the classroom, learning opportunities will be facilitated. It is for this reason that teachers should be knowledgeable and well-informed about the significance of teacher talk and the process of interaction and their relationship with learning. The link between second language acquisition and interaction is strong as supported by many scholars working in this field. Undoubtedly, one of the greatest challenges in the ESL classroom is the development of students' advanced speaking. Teachers will increase and promote their students' language learning provided they better understand the process of interaction. This is because they are the ones expected to initiate, manage, and keep communication going. This implies that it is the teacher who plays the crucial role in making classroom interaction significant and worthy without neglecting the part played by learners. While interacting, learners practise the target language and this makes them fluent. The achievement communicative strategies used helped students who had 
difficulty expressing themselves to organize their thoughts to convey their message. Through this, their interaction with the lecturers deepened.

\subsubsection{Developing Learner Autonomy}

Learner autonomy is one of a number of closely related concepts within the general paradigm of learner-centred education. The notion of learner autonomy is a direct consequence of the increasing preoccupation with learner-centeredness in educational policies and practices, a preoccupation that has had its corresponding formulation in second language acquisition (SLA) research and teaching over the last two and a half decades. The shift of focus from teacher-centred approaches to learner-centred approaches underscores the relevance of self-directed learning where learners find the opportunity to improve their skills and become independent in their learning process. As Faucette (2001, p. 389) puts it "autonomous learning seeks to equip learners with tools that will best serve them once they are on their own and to facilitate their self-directed learning outside the classroom". According to Færch and Kasper (1983), the use of communication strategies can help learners to "bridge" pedagogic and non-pedagogic situations (p. 56). In line with this, Faucette (2001) maintains that learner autonomy is the ability to bridge this gap which can be developed through instruction. The analysis showed that achievement strategies helped students to express themselves with little support from the lecturer, an indication that learners learnt language with some level of autonomy.

\section{Conclusion}

It has been revealed in this study that lecturers and students tend to use various communicative strategies in their attempt to express themselves well. This can be achieved by using literal translation, code-switching, appeal for help, and restructuring. The study has revealed that achievement communicative strategies allow lecturers and students to continue in their conversation, which affords them the chance to hear more input and produce new utterances which help to sustain the conversations. It would be valuable to note that the use of these strategies has remarkable teaching and learning effects on both lecturers and students. Again, the study has revealed that the strategies are useful for learning a language and they should be applied in real communication contexts. Furthermore, the present study has established that Communication Skills is best learned and taught through interaction. Lastly, the achievement strategies are very important for communication and so should be taught to learners as they are very useful for building their communicative competence.

The study was limited in many aspects: First, some students studying Communication Skills from only two out of 20 public universities were recorded; more classes could have participated. Second, more universities could have also been added in order to examine the range of achievement strategies used in the classroom. Third, while some other communicative strategies were present in the data, they were not examined because they were not the focus of the study, and Fourth, the instruments were only lesson recording and observation. An examination of all the strategies would foster an understanding of their use, 
especially in teaching and learning. Based on the limitations, there can be studies conducted in other universities in Ghana to examine lecturers' and students' use of all communicative strategies in English-medium classrooms. Again, the instruments can be expanded to include interviews and questionnaire so that an elaborate mixed methods study can be conducted on the use of communicative strategies in the university classroom. The findings from such studies could be used to influence curriculum planning to include communicative strategy knowledge to make both students and lecturers aware of the significance of communicative strategies in learning Communication Skills and ESL in general.

\section{References}

Abura J. A. (1998). Verbal communication in the classroom: What Christian educators can do to help their students. University of Eastern Africa.

Adjei, A. F. (2010). Motivation for code-switching in the classroom-the case of rural primary school. Journal of African Cultures and Languages, 1(1), 21-28.

Alawi, R. A. A. (2016). Communication strategies used by Omani EFL students. Pyrex Journal of English and Literature, 2(1), 1-11. www.pyrexjournals.org/pje

Aliakbari, M. \& Allvar, N. K. (2009). Communication strategies in the written medium: The effect of Language proficiency. Linguistik Online, 40(4), 4-13. https://doi.org/10.13092/lo.40.428

Allwright, R. \& Bailey, K. (1991). Focus on the language classroom: An introduction to classroom research for language teachers. Cambridge University Press.

Alptekin, C. (2002). Towards intercultural communicative competence in ELT. ELT Journal, 56(1), 57-64. https://doi.org/10.1093/elt/56.1.57

Amedahe, F. K. (2002). Fundamentals of educational research methods. University of Cape Coast.

Arjpru, T \& Chattiwat, W. (2017). The development of task-based speaking and communication strategies instructional model to enhance speaking competence of 1st Year EIC students. Rangsit Journal of Educational Studies, 4(2), 72-89. https://doi.org/10.14456/rjes.2017.10

Babbie, E. R. (2015). The practice of social research (14th ed.). Cengage Learning.

Bialystok, E. (1990). Communication strategies: A psychological analysis of secondlanguage use. Blackwell.

Brown, H. D. (2000). Principles of language learning and teaching (4th ed.). Longman.

Canale, M. \& Swain, M. (1980). Theoretical bases of communicative approaches to second language teaching and testing. Applied Linguistics, 1, 1-47. https://doi.org/10.1093/applin/i.1.1 
Creswell. J. (2014). Research design: Qualitative, quantitative, and mixed methods approaches (4th ed.) SAGE.

Dobao, A. M. \& Martínez, I. M. (2007). Negotiating meaning in interaction between English and Spanish speakers via communication strategies. Atlantis, 29(1), 87-105. https://www.jstor.org/stable/41055267

Dörnyei, Z. (1995). On the teachability of communication strategies. TESOL Quarterly, 29(1), 55-85. https://doi.org/10.2307/3587805

Dörnyei, Z. \& Scott, M. L. (1997). Communication strategies in a second language: Definitions and taxonomies. Language Learning, 47(1), 173-210. https://doi.org/10.1111/0023-8333.51997005

Dörnyei, Z. \& Thurrell, S. (1991). Strategic competence and how to teach it. ELT Journal, 45(1), 16-23. https://doi.org/eltj/article-abstract/45/1/16/2756598

Dută, N. \& E. Rafaila. (2014). Training the competences in higher education: A comparative study on the development of relational competencies of university teachers. Procedia - Social and Behavioral Sciences, 128, 522-526. https://doi.org/10.1016/j.sbspro.2014.03.199

Færch, C. \& Kasper, G. (1983). Plans and strategies in foreign language. In Færch, C. \& Kasper, G. Strategies in interlanguage communication (pp. 20-60). Longman.

Faucette, P. (2001). A pedagogical perspective on communication strategies: Benefits of training and an analysis of English language teaching materials. Second Language Studies, 19(2), 1-40.

Habeeb, D. (2014). Effective communication skills in teaching-learning process. In Fenn, V. (Ed.), Grammar and Grammar Teaching: Changing Perspectives 2, 53-57.

Hedge, T. (2000). Teaching and learning in the language classroom. Oxford University Press.

Huff, L. \& Christensen, L. L. (2018). The role of language and communication in the education of English learners with significant cognitive disabilities. ALTELLA Brief, 7, 1-8. Retrieved from www.altella.wceruw.org

Hymes, D. H. (1972). On communicative competence. In Pride, J. B. \& Holmes, J. (Eds.), Sociolinguistics: Selected readings (pp. 269-293). Penguin.

Jahbel, K. (2019). Communication difficulties faced by Undergraduate Libyan students. International Seminar on Language, Education, and Culture, 147-154. https://doi.org/10.18502/kss.v3i10.3896

Jamshidnejad, A. (2020). The nature and functions of communication strategies in L2 oral communication. In Jamshidnejad, A (Ed.), Speaking English as a second Language: Learners' problems and coping strategies (pp. 229-251). Palgrave.

Johnstone, R. (1989). Communicative interaction: A guide for language teachers. CILT. 


\section{Ml Macrothink}

Kenza, S. (2020). An examination into the effect of learners' mother tongue interference on the occurrence of code-switching in an English as a foreign language class: the case of third year English majors at Biskra University. http://archives.univ-biskra.dz/bitstream/123456789/16101/1/Kenza_SAOU.pdf

Khanji, R. (1996). Two perspectives in analyzing communication strategies. International Review of Applied Linguistics in Language Teaching, 34(2), 144-155. https://eric.ed.gov/?id=EJ529518

Kim, M. (2019). Communication Strategy of Korean EFL Learners. Unpublished Masters Thesis, St. Cloud State University.

Lafford, B. (2004). The effect of the context of learning on the use of communication strategies by learners of Spanish as a second language. Studies in Second Language Acquisition, 2(26), 201-225. https://www.jstor.org/stable/44486769

László, K. (2017). The use of communication strategies in English language education. International Journal of Humanities and Social Development Research, 5-14.

Mali, Z. O. (2007). Exploring communication strategy use by learners of IsiZulu in synchronous computer-mediated communication (S-CMC) Unpublished $\mathrm{PhD}$ Thesis, University of Iowa. https://doi.org/10.17077/etd.odovtme1

Manchón, R. (2000). Fostering the autonomous use of communication strategies in the foreign language classroom. Links and Letters, 13-27. 38997682. (core.ac.uk)

Mariani, L. (2010). Communication strategies: Learning and teaching how to manage oral interaction. Learning Paths.

Masithoh, H. Fauziati, E., \& Supriyadi, S. (2018). Communication strategies used by the students on the perspective of language proficiency. International Journal of Multicultural and Multireligious Understanding, 5(5), 21-32. https://doi.org/10.18415/ijmmu.v5i5.257

Meyerhoff, M. (2015). Introducing sociolinguistics. Routledge.

Nakatani, Y. (2006). Developing an oral communication strategy inventory. The Modern Language Journal, 90(2), 151-168. https://doi.org/0026-7902/06/151-168

Nunan, D. (1989). Designing tasks for the communicative classroom. Cambridge University Press.

O’Leary, Z. (2017). The essential guide to doing your research project. Sage.

Saif, S. (2002). A needs-based approach to the evaluation of the spoken language ability of the international teaching assistants. Canadian Journal of Applied Linguistics, 5(1), 145-167. Journals.lib.unb.ca/index.php/CJAL/article/view/19844

Sato, T., Yujobo, Y. J., Okada, T. \& Ogane, E. (2019). Communication strategies employed by low-proficiency users: Possibilities for ELF-informed pedagogy. Journal of English as a Lingua Franca, 8(1), 9-35. https://doi.org/10.1515/jelf-2019-2003 
Shenton, A. K. (2004). Strategies for ensuring trustworthiness in qualitative research projects. Education for Information, 22(2), 63-75.

Tarone, E. (1980). Communication strategies, foreigner talk and repair in interlanguage. Language Learning, 30(2), 417-428. https://doi.org/10.1111/j.1467-1770.1980.tb00326.x

Trihastuti, Y. A. \& Zamzani, Z. (2018). The role of communication strategies in the classroom communication. In Panuju, R. (Ed.), Proceedings of the International Conference of Communication Sconce Research (pp. 295-297). Atlantis.

Trosborg, A. (1994). Interlanguage pragmatics. Mouton.

Wagner, J. \& Firth, A. (1997). Communication strategies at work. In G. Kasper, \& E. Kellerman (Eds.), Communication strategies: Psycholinguistic and sociolinguistic perspectives (pp. 323-344). Longman.

Walsh, S. (2002) Construction or obstruction: Teacher talk and learner involvement in the EFL classroom. Language Teaching Research, 6(1), 3-23.

https://doi.org/10.1191/13621688021r095oa

Wei, L. \& Martin, P. (2009). Conflicts and tensions in classroom codeswitching: An introduction. International Journal of Bilingual Education and Bilingualism, 12(2), 117-122. https://doi.org/10.1080/13670050802153111

Yin, R. K. (2003). Case study research: Design and methods $\left(3^{\text {rd }}\right.$ ed). SAGE.

Yule, G. (2020). The study of language. Cambridge University Press.

\section{Copyright Disclaimer}

Copyright for this article is retained by the author(s), with first publication rights granted to the journal.

This is an open-access article distributed under the terms and conditions of the Creative Commons Attribution license (http://creativecommons.org/licenses/by/4.0/). 